\title{
Programação em Scratch na Sala de Aula: investigações sobre a construção do conceito de ângulo
}

\author{
Kátia Coelho da Rocha ${ }^{1}$, Marcus Vinícius de Azevedo Basso ${ }^{2}$ \\ ${ }^{1}$ Programa de Pós-Graduação em Informática na Educação - Universidade Federal do \\ Rio Grande do Sul (UFRGS) \\ Caixa Postal 15.064 - 91.501-970 - Porto Alegre - RS - Brasil \\ ${ }^{2}$ Programa de Pós-Graduação em Informática na Educação - Universidade Federal do \\ Rio Grande do Sul (UFRGS) \\ Caixa Postal 15.064 - 91.501-970 - Porto Alegre - RS - Brasil \\ katiacoelhorocha@gmail.com, mbasso@ufrgs.br
}

\begin{abstract}
This article describes an investigation on the use of Scratch in the construction of the concept of angle, answering the question of research: What are the first notions of students in relation to the concept of angle in programming activities in Scratch? It presents a qualitative study, characterized as a multiple case study, carried out with 16 elementary school students from a public school in São Leopoldo. The theoretical contribution is based on the studies of Papert and Gérard Vergnaud. The results point to possibilities of the software as an instrument that assists in the understanding of the concept of angle in view of the different situations in which the subject manipulates Scratch
\end{abstract}

Resumo. Este artigo descreve uma investigação sobre o uso do Scratch na construção do conceito de ângulo, atendendo à questão de pesquisa: Quais as primeiras noções dos alunos em relação ao conceito de ângulo em atividades de programação no Scratch? Apresenta um estudo de caráter qualitativo, caracterizado como um estudo de casos múltiplos, realizado com 16 alunos do Ensino Fundamental de uma escola da rede pública de São Leopoldo. O aporte teórico está fundamentado nos estudos de Papert e de Gérard Vergnaud. Os resultados apontam possibilidades do software como um instrumento que auxilia na compreensão do conceito de ângulo diante das diversas situações em que o sujeito manipula o Scratch.

\section{Introdução}

O uso de atividades de programação em sala de aula vem sendo estimulado há muito tempo. Papert (1985) na década de 70 já apresentava perspectivas de desenvolvimento do pensamento através da construção de programas em LOGO. Atualmente, a área da computação estima que no futuro haverá carência de programadores, por isso têm estimulado, através de campanhas, a disseminação da programação. Além disso, pesquisas na área do desenvolvimento do Pensamento Computacional (WING, 2006; RESNICK et all, 2009) demonstram a importância do pensamento por procedimentos aplicado em diferentes situações e que contribuem para o desenvolvimento de habilidades variadas. 
VIII Congresso Brasileiro de Informática na Educação (CBIE 2019)

Anais do XXV Workshop de Informática na Escola (WIE 2019)

Programar permite ao sujeito utilizar o computador como um "objeto para-sepensar-com" (PAPERT, 1985, p. 216). Assim, ele se torna uma ferramenta para desenvolver atividades mais ricas, que auxilia o sujeito a pensar sobre os conceitos, manipulando-os em projetos que são pessoalmente significativos. Resnick trabalhou com Papert em projetos do LOGO e compartilha de seus propósitos; para ele, a programação auxilia na formação de uma geração mais criativa, que pensa sistematicamente e expressa suas ideias, tornando-se seres mais ativos, que colaboram com o outro e produzem seu próprio conteúdo (RESNICK et al., 2009).

Nessa perspectiva, Resnick criou o Scratch como uma linguagem de programação visual mais simples, tornando a ideia da ciência da computação acessível, estimulando o pensamento computacional, a aprendizagem em um ambiente motivador e criativo que permite a exploração, a descoberta e a possibilidade de reflexão sobre o próprio pensamento (MARJI, 2014; RESNICK et al., 2009).

Desde a sua criação o Scratch tem motivado pesquisas na área da educação matemática. Para essa pesquisa, optou-se por fazer um uso dirigido do software com um olhar mais aguçado sobre o pensamento matemático durante o ato de programar. Assim, para esse artigo, buscou-se atender a seguinte questão de pesquisa: Quais as primeiras noções dos alunos em relação ao conceito de ângulo em atividades de programação no Scratch? Essa questão faz parte de uma pesquisa de mestrado em que se optou por investigar como os alunos, que ainda não tiveram contato formal na escola com o conceito de ângulo, constroem esse conceito e expressam seus pensamentos matemáticos através do Scratch (ROCHA, 2017).

Apresenta-se, nesse artigo, parte dos resultados dessa pesquisa. Na seção 2 está uma discussão sobre como o conceito de ângulo aparece no Scratch. Na seção 3 está o aporte teórico que fundamenta a análise dos dados. Na seção 4 são apresentados e discutidos alguns dos resultados e na seção 5 as considerações finais.

\section{O ângulo no Scratch}

O Scratch baseia-se no LOGO e utiliza a mesma estrutura de pensamento proposta por ele. Papert (1985) destaca que o LOGO trabalha com uma geometria denominada de Geometria da Tartaruga, que "é um estilo computacional de geometria." (PAPERT, 1985, p. 77). Ela é assim denominada porque seu sprite é uma tartaruga. O sprite do Scratch é como a tartaruga do LOGO e tem as mesmas características que ela: é dinâmico, tem uma posição, pois está em algum lugar do palco, e tem uma orientação, ou seja, está voltado para alguma direção. Dentro desses aspectos observa-se que ele, assim como a tartaruga, é semelhante a uma pessoa. A semelhança da tartaruga com a pessoa permite que ela possa "[...] servir como a primeira representação da matemática formal para a criança” (PAPERT, 1985, p. 78).

Nesse caso, a criança aprende dentro de um ambiente em que é levada a desenvolver ideias sobre o seu próprio movimento e que podem ser aplicadas nos programas para movimentar a tartaruga, ou seja, aprender geometria estaria associado a pensar com o seu próprio corpo (PAPERT, 1985). Esse pensamento envolvido é chamado de pensamento por procedimentos, já que leva o sujeito a pensar sobre o objeto, em como ele poderia ser representado através da linguagem computacional. (VITALE, 1991). 
VIII Congresso Brasileiro de Informática na Educação (CBIE 2019)

Anais do XXV Workshop de Informática na Escola (WIE 2019)

No Scratch um ângulo é executado pelo bloco "gire $n$ graus", que é um bloco de movimento relativo, pois faz com que o sprite gire a partir de sua posição e direção atual; pode-se dizer que ele carrega consigo sua trajetória anterior. Utilizar esse bloco leva o aluno a pensar sobre ângulo e como o computador irá desenhá-lo, provocando o pensamento sobre o próprio objeto, suas características e não sobre sua definição propriamente dita (PAPERT, 1985; VITALE, 1991). O uso dos valores numéricos utilizados no comando "gire" está atrelado a diversas situações em que eles são usados e podem ser compreendidos através de experimentações.

Pensar a matemática através de procedimentos é uma forma de propiciar ao aluno pensar sobre a matemática, trazer outras ferramentas ao seu arsenal, e não substituir as já existentes. Papert (1985) ressalta isso como uma forma de estimular a habilidade humana a operar com diversos conhecimentos, ampliando os caminhos para a reflexão. Nesse sentido, desenhar um polígono permite ao sujeito refletir sobre ele e, a partir de suas experiências, identificar que o procedimento envolve pensar sobre os ângulos externos do polígono. Ao desenhar um quadrado, por exemplo, o sujeito pode descrever o procedimento apenas alternando os blocos "mova $n$ passos" e "gire $90^{\circ}$ ". Ao desenhar um triângulo equilátero, por exemplo, esse mesmo pensamento não poderá ser utilizado. A figura 1a demonstra essa tentativa com seu respectivo resultado, e a figura $1 \mathrm{~b}$ demonstra o procedimento correto.

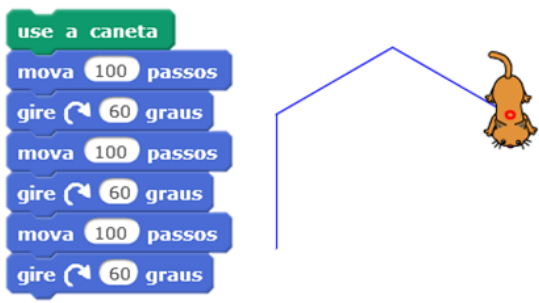

(a)

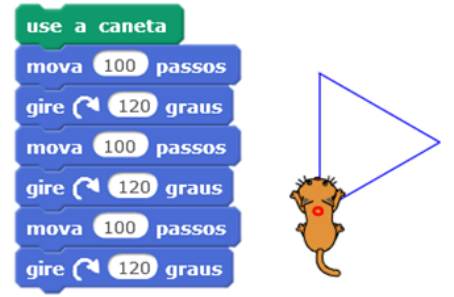

(b)

Figura 1. Programa para triângulo equilátero

Observa-se nos procedimentos da figura $1 \mathrm{~b}$ que, ao final da construção, o sprite terá dado um giro de $360^{\circ}$. Esse é o chamado Teorema do Giro Completo da Tartaruga proposto por Papert (1985, p. 101): "Se uma tartaruga percorre um caminho ao redor do perímetro de qualquer área e termina no mesmo estado em que começou, então a soma total de todos os giros será de 360 graus".

O sprite oficial (figura 2a) e mais conhecido do Scratch é o gato, que está em uma posição menos convencional para os alunos, pois ele está ao mesmo tempo com o corpo virado para o lado e a cabeça de frente para o usuário, representando uma orientação diferente da pessoa que está em frente ao computador. Em virtude disso, para essa pesquisa, o sprite foi alterado nas primeiras atividades. Para a escolha considerouse um gato que estivesse em uma posição semelhante à da tartaruga proposta por Papert e, ao iniciar a atividade, apontasse para a posição $0^{\circ}$ (figura $2 \mathrm{~b}$ ). Além disso, o sprite recebeu uma marca para indicar seu centro de rotação e a posição da caneta.

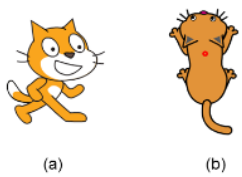

Figura 2. Sprite oficial $X$ sprite utilizado 
VIII Congresso Brasileiro de Informática na Educação (CBIE 2019)

Anais do XXV Workshop de Informática na Escola (WIE 2019)

\section{A Teoria dos Campos Conceituais}

A Teoria dos Campos Conceituais foi criada por Gérard Vergnaud e tem suas origens na teoria psicogenética de Jean Piaget. Ao desenvolver sua própria teoria, Vergnaud demonstra interesse pelo processo de ensino e aprendizagem da matemática no contexto escolar, investigando como o sujeito aprende em ação. O foco está nas representações, nos esquemas e conceitos utilizados pelos alunos para resolver problemas, oferecendo suporte a estudos do desenvolvimento e da aprendizagem científica e técnica em diversas áreas. Considerando isso, pode-se afirmar que, durante atividades de programação, o sujeito está em constante ação e é levado a resolver situações variadas que lhe permitem combinar e descobrir diferentes aspectos dos conceitos envolvidos. Por isso, essa teoria mostra-se uma ferramenta para auxiliar o professor na compreensão desses processos e na proposição de novas situações que auxiliem o aluno na construção de conceitos através da programação (ROCHA; BASSO, 2017).

Vergnaud admite que o processo de aprendizagem é longo e se desenvolve a partir das diferentes situações que ocorrem dentro e fora da escola. As situações levam o sujeito a passar por etapas que envolvem filiações, pois os novos conhecimentos apoiam-se em conhecimentos anteriores, e rupturas, já que, em alguns momentos, é necessário abandonar as ideias e ações anteriores para a construção de novas competências (VERGNAUD, 2011).

Uma situação consiste em uma tarefa, que pode ser prática ou teórica, que leve o sujeito a traçar relações, explorar, criar hipóteses e verificá-las, a fim de obter uma solução. Desta forma, a Teoria dos Campos Conceituais não reduz um conceito à sua definição, mas defende que "é através das situações e dos problemas a resolver que um conceito adquire sentido para a criança" (VERGNAUD, 1993, p. 1). O sentido que permite à criança compreender um conceito refere-se aos esquemas que são despertados a partir de uma situação.

O conceito de esquema criado por Piaget é complementado por Vergnaud quando o define como

[...] a organização invariante do comportamento para uma classe de situações dada. É nos esquemas que se devem pesquisar os conhecimentos-em-ação do sujeito, isto é, os elementos cognitivos que fazem com que a ação do sujeito seja operatória. (VERGNAUD, 1993, p. 2).

Portanto, para o autor, um esquema é um conjunto de ações, de coleta de dados e controle que variam de acordo com cada situação, organizando as ações e o pensamento. Um programa criado no Scratch pode ser considerado um exemplo de esquema; ele demonstra a ação do sujeito para a resolução de uma situação e pode ser empregado em situações da mesma classe (ROCHA; BASSO, 2017).

Sobre às classes de situações, citadas anteriormente, pode-se afirmar que os esquemas se enquadram perfeitamente na primeira classe de situações. Já na segunda classe também há uma estruturação em esquemas, porém, como não há um esquema específico para aquela situação, o sujeito busca em seu repertório esquemas que tenham alguma afinidade com a situação dada. Neste caso, o esquema pode não ser efetivo, sendo necessária a mudança, modificação, combinação de esquemas ou acréscimo de elementos cognitivos, criando novos esquemas. 
Um esquema está sempre apoiado em uma conceitualização implícita. Mesmo que o sujeito não saiba expressar esse conceito, ele precisa compreendê-lo para que seu esquema funcione corretamente. Os conhecimentos contidos num esquema são denominados conceitos-em-ação e teoremas-em-ação. O uso do termo "em ação" por Vergnaud, como o nome se refere, corresponde à ideia de que o sujeito usa esses conhecimentos durante a situação. Os conceitos-em-ação são uma categoria de pensamento, não sendo necessariamente conceitos científicos; são eles que permitem ao sujeito verificar se uma determinada informação é ou não pertinente para enfrentar uma situação. Os conceitos-em-ação são os conceitos mobilizados pelo sujeito para pensar na situação.

\section{Resultados e Discussão}

Destaca-se nesse artigo duas das atividades que compõem a dissertação de mestrado e que apresentam as primeiras noções dos alunos acerca do conceito de ângulo. É uma pesquisa qualitativa que se caracteriza como um estudo de casos múltiplos, no qual os casos individuais serviram para compor o conjunto das impressões dos alunos a respeito do conceito de ângulo em suas primeiras experimentações no Scratch.

As atividades foram desenvolvidas de junho a agosto de 2016 em uma escola da rede municipal de São Leopoldo. Os alunos eram atendidos semanalmente, durante um período de 50 minutos dentro da carga horária do componente curricular de Matemática. Os alunos pertenciam a um $6^{\circ}$ ano do Ensino Fundamental formado por 16 alunos que tinham entre 10 e 12 anos.

As atividades eram realizadas individualmente no Scratch e em uma página wiki privada, criada para disponibilizar aos alunos o roteiro das aulas. $\mathrm{Na}$ wiki cada aluno tinha sua página individual para fazer seus registros antes e após cada atividade, tais registros eram guiados por questões que serviram de inspiração para possíveis compreensões do pensamento dos alunos, já que a dinâmica e a quantidade de alunos atendidos ao mesmo tempo não permitiriam a realização de entrevistas com todos os alunos de forma concomitante.

A fim de guiar as análises das produções dos alunos foram elaboradas hipóteses que representam possíveis pensamentos e soluções dos alunos enquanto realizavam cada atividade.

O software utilizado foi o Scratch 2 já instalado nas máquinas que também continham os projetos do Scratch que serviram de base para as atividades que serão descritas e analisadas a seguir.

\subsection{Atividade: Desafio A}

O Desafio A consistia em criar um algoritmo para que o gato chegasse até o biscoito. A figura 3 mostra a tela inicial da qual cada aluno deveria partir para criar seu algoritmo. 
VIII Congresso Brasileiro de Informática na Educação (CBIE 2019)

Anais do XXV Workshop de Informática na Escola (WIE 2019)

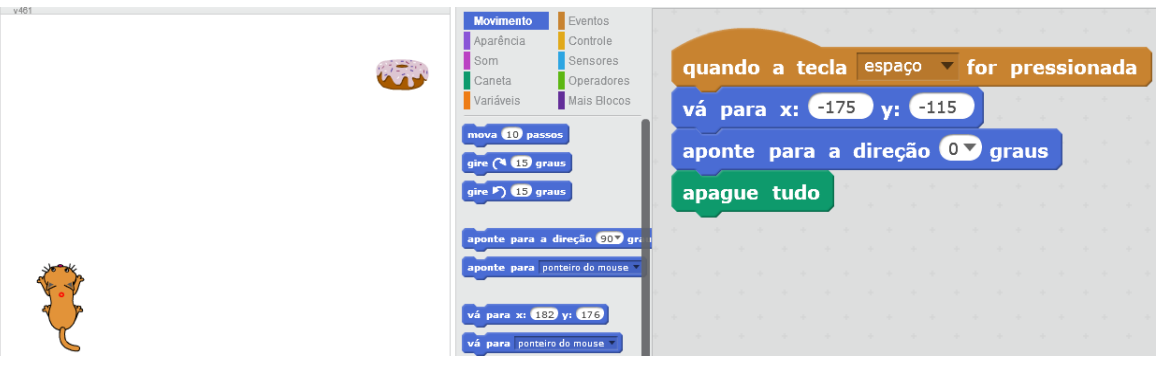

Figura 3. Desafio A

Foram estabelecidas as seguintes hipóteses para essa atividade:

Hipótese 1 - Os alunos farão o trajeto do gato através de uma diagonal.

Hipótese 2 - Os alunos conseguirão programar o gato.

Hipótese 3 - Os alunos questionarão o que representa a programação já presente na área de comandos.

Hipótese 4 - Os alunos farão testagens para descobrir o giro e a quantidade de passos necessários para o deslocamento. seguintes:

A questões propostas aos alunos antes de realizar a programação foram as

Como você fará o deslocamento do gato?

O que você precisa "ordenar" ao gato?

Após os alunos deveriam abrir o projeto do desafio e iniciar a sua programação. Ao finalizar a programação os alunos deveriam retornar a wiki e responder a seguinte questão:

Como você descreve a ação do gato quando é executado o comando mova um determinado número de passos?

\subsection{Análise: Desafio A}

Ao iniciar as programações no Scratch, os alunos faziam testagens constantes dos valores de giro e movimento. Esse fato mostra o início de apropriação da linguagem de programação pelos alunos e também mostram o quanto essa situação levou os sujeitos a testar, explorar e refletir para obter uma solução, conforme é expresso por Vergnaud (1993).

A maioria dos alunos não fazia a montagem da sequência de comandos, deixando os blocos desencaixados, conforme se pode observar na figura 4 .

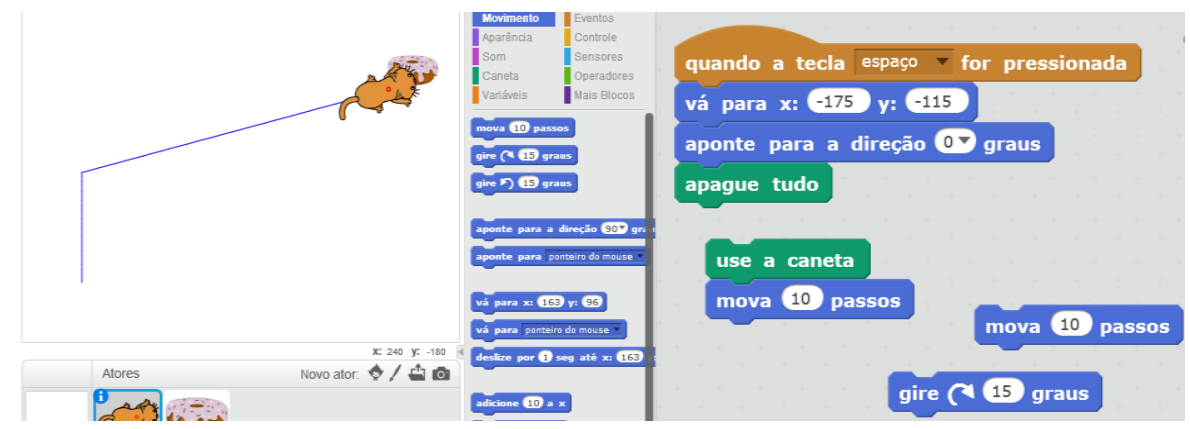

Figura 4. Comandos desconectados 
VIII Congresso Brasileiro de Informática na Educação (CBIE 2019)

Anais do XXV Workshop de Informática na Escola (WIE 2019)

Ao deixar os blocos desencaixados, esses alunos mostraram que ainda não tinham se apropriado da linguagem e da construção de um pensamento por procedimentos (Papert, 1985).

Outros alunos mostraram uma estruturação um pouco mais elaborada já na descrição anterior à programação, como foi o caso da aluna W: Eu farei o deslocamento do gato de forma que ele fosse reto e depois virasse para a direção do biscoito. Mesmo que sua descrição ainda não represente todo o algoritmo, já se identifica uma organização do pensamento em relação à ação a ser executada e a necessidade de um giro.

$\mathrm{O}$ aluno $\mathrm{O}$ demonstrou sua compreensão de que o programa pode ser manipulado e modificado, ao concluir a tarefa proposta abriu-a novamente para criar uma variação, conforme pode ser visto na figura 5 .

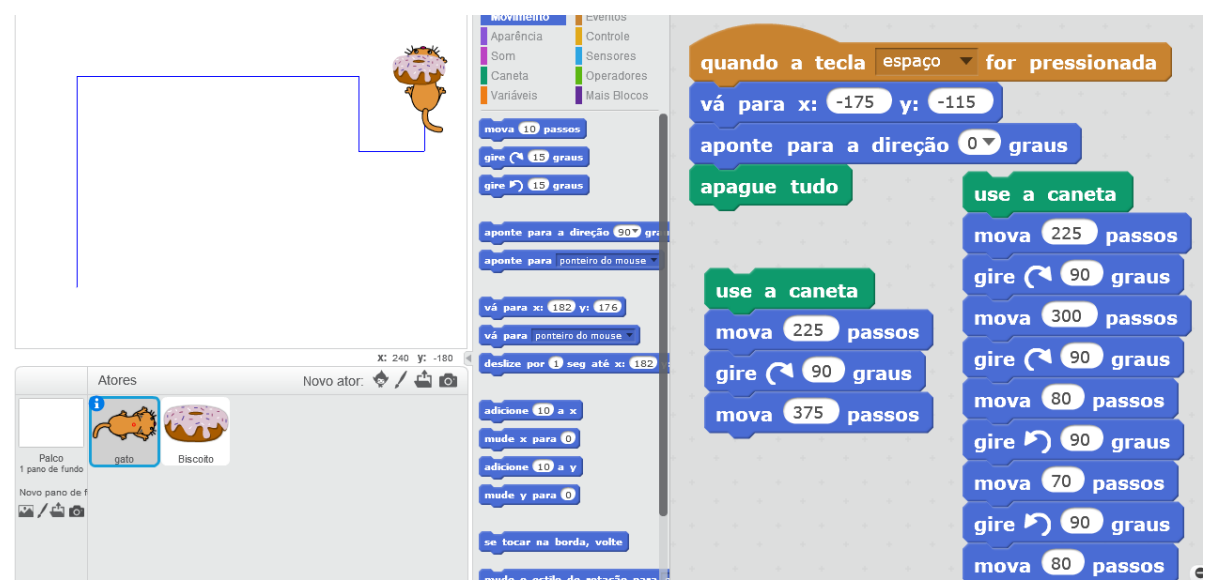

Figura 5. Programa manipulável

Em sua explicação sobre a elaboração desse novo caminho, $\mathrm{O}$ afirmou que havia utilizado o programa anterior e que, para produzir o novo desenho, era só alterar o final. O giro eu sabia que era 90, só testei os passos. A fala de $\mathrm{O}$ demonstra sua percepção dos procedimentos, além de reforçar sua compreensão em relação ao giro de $90^{\circ}$ e ao fato de que este se dá a partir da posição inicial do sprite. Em diálogo com o aluno, este afirmou $360^{\circ}$ eu já ouvi falar que é uma volta toda, já ouvi falar bastante nisso, ai eu fui calculando pra ver. 360 aí vai pra 180, ai vai pro 90, dai vai pro 45 e assim vai indo. As explicações de $\mathrm{O}$ mostram seu esquema para ângulo identificando situações em que o conceito está inserido, neste caso a atividade de programação; seus conceitosem-ação e teoremas-em-ação como "a volta é $360^{\circ}$ " e todas as relações que ele estabelece a partir dessa compreensão.

Em relação às hipóteses iniciais, identifica-se que a hipótese 1, os alunos farão o trajeto do gato através de uma diagonal, foi verificada apenas com a construção de um aluno, já que os demais alunos procuraram um trajeto cujas linhas fossem paralelas à borda da tela, buscando constantemente, através de testagens, uma forma de fazer o gato "girar reto", ou seja, 90 . Sendo assim, apenas a hipótese 3 que previa que os alunos questionariam o que representava a programação já presente na área de comandos, não foi verificada.

Ao final da atividade, diante das sucessivas experimentações, percebia-se nos alunos um algoritmo mais organizado, utilizando os encaixes dos comandos e 
VIII Congresso Brasileiro de Informática na Educação (CBIE 2019)

Anais do XXV Workshop de Informática na Escola (WIE 2019)

demonstrando um início de compreensão do software e da linguagem a ele associada. $\mathrm{O}$ conceito de ângulo ainda é muito primário, sendo resultado de testagens indicando que ainda não possuem as competências necessárias para lidar com essa classe de situações (VERGNAUD, 1993). Os alunos demonstraram identificar a necessidade de um giro para algum lado, mas o que esse valor representava ainda não era expresso.

Um dos alunos apresentou condutas que indicaram sua compreensão a respeito do giro de $90^{\circ}$ sem nenhuma testagem o que foi chamado de "número mágico". A expressão "número mágico" está baseada nas pesquisas de Búrigo e Basso (1992) sobre o LOGO, onde os autores identificaram que os alunos utilizavam esses números mesmo sem compreender o princípio de composição dos algarismos e o conceito de ângulo, porque conheciam o resultado que estes apresentavam na tela. Nessa análise, usa-se a expressão com o mesmo sentido atribuído pelos autores, considerando a relação que os alunos estabelecem entre o valor do ângulo e o resultado expresso na tela, mesmo que não demonstrem compreensão do conceito de ângulo.

\subsection{Atividade: Desafio B}

O Desafio B consistia em criar um algoritmo que levasse o gato do ponto de partida até o biscoito sem tocar no piano. A figura 6 representa a tela do Scratch com o desafio.

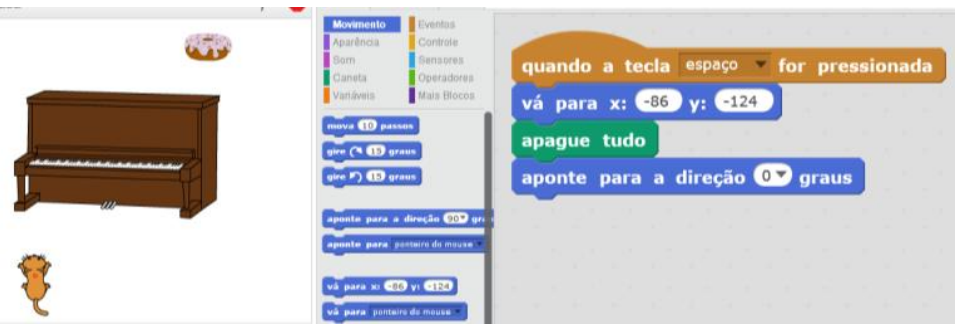

Figura 6. Desafio B

Foram determinadas a seguintes hipóteses:

Hipótese 1 - Os alunos farão testagens para descobrir quantos passos o gato precisa se mover e quantos graus precisa girar para não bater no piano.

Hipótese 2 - Alguns alunos estarão em busca, durante as testagens, do ângulo de $90^{\circ}$.

Hipótese 3 - Alguns alunos questionarão o que significa "grau".

Os questionamentos feitos aos alunos antes da programação foram:

Como você fará o deslocamento do gato?

O que você precisa "ordenar" ao gato?

Quais os blocos necessários?

Após a atividade foram propostas a seguintes questões:

Qual a sua dificuldade durante a realização da tarefa?

Como você descreve a ação do gato quando é executado o comando gira?

\subsection{Análise: Desafio $B$}

As respostas dos alunos às questões que antecediam a programação apontam para o uso dos seus conceitos-em-ação compreendidos na atividade anterior (VERGNAUD, 1993). 
Esses alunos indicavam a necessidade dos blocos "mova" e "gire", mostrando uma organização mais próxima de um algoritmo, como demonstram as descrições: preciso ordenar que o gato gire e ande até o biscoito se deslocando do piano (ALUNA Z), preciso ordená-lo girar várias vezes 15 graus e avançar 400 passos com a caneta (ALUNO L), preciso ordenar ao gato que ele vá para a esquerda depois reto e virasse para direita em direção onde está o biscoito (ALUNA W).

Outro fato comum são as constantes testagens para a descoberta dos valores, que era visível no momento em que os alunos programavam com sucessivos cliques e alterações no bloco gire. Além disso, afirmações como eu fui testando (ALUNA Z), ou ainda, mostrando suas estratégias, eu boto um valor, ai vou trocando até ficar na posição que eu quero (ALUNO L), reforçam o empenho dos alunos em encontrar o valor que representasse o movimento desejado, confirmando a hipótese 1. Essas ações também corroboraram para que fossem identificados esses esquemas que mostram a organização de seus pensamentos e que ainda precisam de mais situações para acomodar esse conceito.

As alunas W e S não fizeram testagens para os giros de $90^{\circ}$, pois identificaram um "giro reto" durante o trajeto a ser realizado. Ao justificar o uso do giro de $90^{\circ}$, expressões como 90 fica reto (Aluna S) e $90^{\circ}$ é pra girar de lado (Aluna W) fazem referência à ideia de que este valor representa um "número mágico". Ao mesmo tempo que falava, W também gesticulava com o corpo para demonstrar sua compreensão, que pode ser visualizada na sequência de imagens da figura 7.

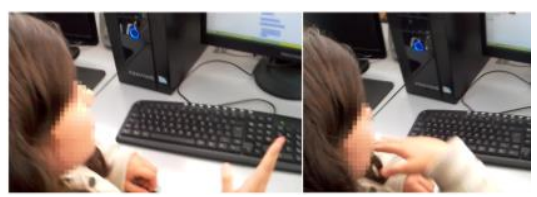

Figura 7. Uso do corpo para demonstrar o giro

O uso do corpo demonstra a possibilidade do software em auxiliar na representação da matemática associando-o aos movimentos corporais do sujeito, conforme destaca Papert (1985). Assim, W demonstra também um início de sua compreensão a respeito do movimento representado pelo valor de $90^{\circ}$, exibindo que esse esquema está relacionado à primeira classe de situações proposta por Vergnaud (1993), em que o aluno já possui as competências necessárias para resolvê-las.

Em relação às hipóteses iniciais do planejamento, identificou-se que apenas a hipótese 3, que previa o questionamento sobre o significado de grau, não foi verificada. A hipótese 2 que estabelecia que alguns alunos estariam em busca, durante as testagens, do ângulo de $90^{\circ}$ foi verificada para 8 alunos.

\section{Considerações Finais}

A partir dos dados coletados e analisados nesse artigo observa-se que os sujeitos apresentaram diferentes compreensões sobre o conceito de ângulo e da própria programação. Em um primeiro momento exploravam livremente, testavam valores não articulando os blocos com sua representação gráfica. Aos poucos alguns sujeitos mostraram identificar números mágicos que representavam movimentos.

Observando os códigos criados, nota-se que eles correspondem a uma sequência que foi elaborada para solucionar uma determinada situação que envolve o conceito de 
VIII Congresso Brasileiro de Informática na Educação (CBIE 2019)

Anais do XXV Workshop de Informática na Escola (WIE 2019)

movimento. Esse movimento exigia dos sujeitos trabalhar com o conceito de deslocamento retilíneo e de giro, relacionando-os com grandezas diferentes. Mesmo sem um conhecimento prévio sobre esses conceitos os alunos mostraram possibilidades de explorá-los, colocando seus conceitos e teoremas em ação para atingir níveis mais elevados de compreensão (VERGNAUD, 1993). Desta forma, o Scratch se mostrou como uma potente ferramenta que permite aos sujeitos refletir sobre o conceito de ângulo e utilizar o próprio corpo como fonte de descoberta, assim como destaca Papert (1985).

As atividades aqui apresentadas mostram um esboço das possíveis contribuições do Scratch para o desenvolvimento e expressão do pensamento matemático. Também inspiram outras reflexões a respeito do conceito de ângulo e do próprio conceito de programa em atividades no Scratch, que pretendem ser investigadas em futuras pesquisas.

\section{Referências}

BASSO, M. V. A.; BÚRIGO, E. Z. A Construção do Sistema Numérico Posicional. In. Psicologia: Reflexão e Crítica. Porto Alegre: Instituto de Filosofia e Ciências Humanas da UFRGS, v.5, n. 1, p. 55 - 65, dez.1992

MARJI, M. Aprender a programar com Scratch. Tradução: Lúcia Kinoshita. São Paulo: Novatec, 2014. 284 p.

PAPERT, S. Logo: computadores e educação. Tradução: José Armando Valente. São Paulo: Brasiliense, 1985. 253 p.

RESNICK, M. et al. Scratch: Programming for all. Communications of the ACM. [s.l.]. n 11, p. 60-67, nov. 2009. Disponível em: <http://web.media.mit.edu/ mres/papers/ Scratch-CACM-final.pdf > . Acesso em: 20 maio 2016.

ROCHA, K. C. Programação em Scratch na sala de aula de Matemática: investigações sobre a construção do conceito de ângulo. 2017. 211 f. Dissertação (Mestrado Profissional em Ensino de Matemática) - Programa de Pós-Graduação em Ensino de Matemática, Instituto de Matemática e Estatística, Universidade Federal do Rio Grande do Sul, Porto Alegre, 2017.

ROCHA, K. C.; BASSO, M. V. A. Teoria dos Campos Conceituais na análise de programação em Scratch. Renote, Porto Alegre, v. 15. n. 2, 2017

VERGNAUD, G. Teoria dos campos conceituais. In Nasser, L. (Ed.) Anais do $1^{\mathrm{o}}$ Seminário Internacional de Educação Matemática do Rio de Janeiro. 1993. p. 1-26. O longo e o curto prazo na aprendizagem da matemática. Educar em Revista, n. Especial 1/2011, Editora UFPR: Curitiba, p.15-27, 2011.

VITALE, B. Computador na escola: um brinquedo a mais? Ciência Hoje, v. 13, n. 77, p. 19-25, out./nov. 1991.

WING, J. M. Computational Thinking. Communications of the ACM, vol. 49, n. 3, p.33-35, mar 2006. 